\title{
Memória e Oralidade: a cantoria de viola e a contação de histórias na Região do Cariri Cearense
}

\author{
Ana Lívia Mendes de Sousa \\ Prefeitura de Juazeiro do Norte, Secretaria de Cultura, Juazeiro do Norte, CE, Brasil \\ analiviaufc@gmail.com
}

Paloma Israely Barbosa de Sá Universidade Federal do Pernambuco, Programa de Pós-graduação de Ciência da Informação, Recife, PE, Brasil palomaisraely@yahoo.com.br

Leilah Santiago Bufrem Universidade Federal da Paraíba, Programa de Pós-graduação de Ciência da Informação, João Pessoa, PB, Brasil santiagobufrem@gmail.com

DOI: https://doi.org/10.26512/rici.v13.n2.28269

Recebido/Recibido/Received: 2019-11-18

Aceitado/Aceptado/Accepted: 24-04-2020

Resumo: Considera que a memória é responsável pela lembrança e transmissão de saberes concorrentes para a construção da cultura das sociedades. Destaca a contação de histórias e a cantoria de viola como manifestações que se utilizam da memória para se manterem vivas e difundirem a cultura (local) como propagação da própria prática das informações transmitidas por meio de seu fazer (versos e histórias). Questiona o que aproxima essas práticas culturais, como se identificam e se constroem na conjuntura local. Tem como objetivo elucidar o diálogo produzido e expresso a partir das relações entre tradição e oralidade, tendo a memória como demarcador da continuidade das gerações, uma forma de reafirmar os valores culturais na localidade do Cariri Cearense e a contribuição desta memória na construção de histórias individuais e coletivas. Realiza análise da literatura sobre o tema, considerando tanto a contação de histórias como a cantoria de viola fatores convergentes, em relação aos seus atores e suas obras, para a construção de um repositório de memórias de sua geração, seu povo, tornando-se elementos de representação e conexão da sociedade e suas facetas sociais, econômicas, políticas e culturais.

Palavras-Chave: memória. contação de histórias. cantoria de viola. Ceará.

Memory and Orality: the viola singing and storytelling in the Cariri region from Ceará

Abstract: It Considers that memory is responsible for the remembrance and knowledge which helps on the construction of the society culture. It highlights the story telling and the viola singing as manifestations which take advantage of memory to keep themselves alive and to dissociate the (local) culture as a propagation of the own practice of transmitted information through its performance (verses and stories). It questions what approximate these cultural practices, how they are identify and construct themselves in the local conjecture. It aims at elucidating the dialogue produced and expressed from the 
relations between tradition and orality being the memory the demarcation of the continuity of generations, a way of reaffirming the cultural values of Cariri from Ceará and the contribution of this memory in the construction of individual and collective stories. It analyzes the literature on the topic, considering that both the story telling as the viola singing congregate, in relation to their actors and their oeuvre, a repository of memories of their generation, their people, becoming elements of representation and society connection and its social, economic, political and cultural facets.

Keywords. Memory. Storytelling. viola singing. Ceará.

Memoria y oralidad: canto de violas y narración de cuentos en la región de Cariri Cearense

Resumen: Considera que la memoria es responsable de recordar y transmitir el conocimiento que ayuda en la construcción de la cultura de las sociedades. Destaca la narración de cuentos y el canto de violas como manifestaciones que utilizan la memoria para mantenerse con vida y difundir la cultura (local) como una propagación de la práctica misma de la información transmitida a través de su creación (versos e historias). Cuestiona qué acerca estas prácticas culturales, cómo se identifican y construyen en la coyuntura local. Su objetivo es dilucidar el diálogo producido y expresado a partir de las relaciones entre la tradición y la oralidad, teniendo la memoria como un marcador de la continuidad de las generaciones, una manera de reafirmar los valores culturales en la localidad de Cariri Cearense y la contribución de esta memoria en la construcción de historias individuales. y colectivo. Realiza un análisis de la literatura sobre el tema, considerando tanto la narración de cuentos como el canto de viola como factores convergentes, en relación con sus actores y sus obras, un depósito de recuerdos de su generación, su gente, convirtiéndose en elementos de representación y conexión de la sociedad y sus facetas sociales y económicas, política y cultural.

Palabras clave. Memoria. Cuentacuentos. viola cantando. Ceará.

\section{Introdução}

A memória, elemento essencial para compreensão do processo informacional, é, em sentido amplo, responsável pela lembrança e transmissão de saberes que auxiliam na construção da cultura das sociedades. Entretanto, o seu registro em suportes e manutenção tem ganhado destaque ao longo dos anos, marginalizando assim a informação transmitida oralmente.

A memória pode ser concebida como sinônimo de recordação ou de representação, como forma de preservar um ato passado, imagens vistas ou falas ouvidas. Estes podem estar associados a contextos individuais ou coletivos, nos quais as memórias se referem não apenas ao sujeito em si, mas ao grupo ou espaço em que ele está inserido. Estas memórias demonstram e descrevem a cultura de um povo por meio de variadas formas, cujo entendimento se mistura ao da oralidade.

A cultura é composta por uma infinidade de manifestações, dentre as quais se destacam aquelas provenientes da oralidade, a cantoria de viola e a contação de histórias. Embora sejam práticas culturais distintas, elas apresentam grandes semelhanças em suas origens, características e conceitos. São manifestações que se utilizam da memória para se manterem vivas e difundem a cultura (local), como propagação da própria prática e das informações transmitidas por meio de seu fazer (versos e histórias). 
Tais manifestações estão presentes em todo o território brasileiro, e muitas delas concentram-se no nordeste do país. No caso desse trabalho o olhar está voltado para o Cariri Cearense, região caracterizada pela diversidade das visões que definem suas fronteiras. A primeira delas, e a que é entendida neste trabalho, leva em conta a abundância de águas e a fertilidade do solo e reduz o Cariri ao ubérrimo vale que se estende ao sopé da chapada do Araripe. Neste espaço estão localizadas as cidades de Crato, Juazeiro do Norte e Barbalha. São conhecidas como o triângulo CRAJUBAR, que abriga a maior população, o maior desenvolvimento, a maior diversidade cultural e é o centro econômico de uma região mais ampla (CARIRY, 2001).

No seio do Cariri estão inúmeros atores que congregam em suas identidades valores da cultura oral. Muitos indivíduos sabem ou já ouviram um trava-língua, uma parlenda, um causo, um repente, uma rima, uma cantiga de roda, ou uma narração de história, entre tantas outras manifestações de uma cultura múltipla e rica em diversidade.

Nesse sentido, busca-se apresentar a contação de histórias e a cantoria de viola em suas semelhanças e representação da memória da cultura Caririense por meio da oralidade. Entre tanta diversidade, pode-se perguntar o que aproxima essas práticas culturais, como se identificam e se constroem na conjuntura local.

Para atingir seu propósito, este trabalho reporta-se às pesquisas realizadas pelas autoras, cujos resultados e conhecimentos produzidos nos seus distintos trabalhos de mestrado permitiram que fosse percebida a aproximação teórica e metodológica entre as duas pesquisas: uma envereda pela cantoria de viola enquanto registro de memória e disseminação da informação, a outra sobre contação de história enquanto transmissora de informação memorialística, identitária e cultural. Ambas as pesquisas fazem parte do universo da Ciência da Informação e sua relação com a memória, além de ter como campo de estudo a região do Cariri cearense.

Objetivou-se, então, elucidar o diálogo produzido e expresso a partir das relações entre a contação de história e a cantoria de viola enquanto manifestações culturais e de registro de memória. Buscou-se a partir de estudos anteriores encontrar a aproximação entre ambas as práticas culturais, seus elementos constitutivos e sua relação com a oralidade e memória. E por se tratar de um aproveitamento dos resultados das dissertações supracitadas, o percurso metodológico deste trabalho se constitui de uma análise de conteúdo da literatura a partir do referencial teórico e dos resultados obtidos nos estudos anteriores. 


\section{Oralidade: a contação de histórias e a cantoria de viola}

Em um país como o Brasil, em que até poucas décadas a maioria da população não era alfabetizada, boa parte das informações e conhecimentos dependiam da memória. Ela exercia papel fundamental na sociedade para reconstruir os fatos individuais e coletivos. Mas com o domínio da escrita por grande parcela da nação e o surgimento da mídia, bem como a ascensão das tecnologias da informação, em todo o mundo, houve uma aproximação pela letra e um esquecimento da voz (RODRIGUES, 2010).

A informação é percebida como uma produção de significados aceitos socialmente e, se considerada a memória como a capacidade de reter certas informações adquiridas anteriormente (MONTEIRO; CARELLI; PICKLER, 2008) e ao retransmiti-las às novas gerações por meio de diferentes registros (sonoros, imagéticos e textuais), com a intermediação de um conjunto de funções psíquicas, fica clara a relação entre informação e memória, realidades que se identificam.

Sampaio (2014), refletindo acerca de estudos de Hobsbawm (1998) sobre as fontes e a memória para a geração do conhecimento, afirma que a memória dita oficial está nos documentos e discursos oficiais das autoridades, porém, ao lado do que a escrita registra, existe outra visão dos acontecimentos recuperáveis através da memória. Ela ainda pondera a respeito da real função da memória, que pode ser construída a partir das falas dos sujeitos que as apresentam dentro de ricas e variadas significações, bem como os objetos que as registram e que estão carregados de valores simbólicos.

Assim, podemos considerar que a memória oral foi por muito tempo a principal forma de transmissão do conhecimento em diversas sociedades na história humana, estas hoje são consideradas primitivas. Sobre as culturas primitivas, Lima (2007) observa que elas não contavam com um modo sistematizado de armazenamento das representações para uma futura reutilização.

A transmissão do conhecimento, no transcorrer do tempo, exigia um contínuo recomeço, uma renovação suscetível a alterações visíveis de geração para geração. A história era feita a partir da capacidade de memorização dos membros do grupo social e de suas preferências. Havia, portanto, um registro "incerto" da realidade, fortemente filtrada pelo sujeito da ação. A mediação desse sujeito, nesse tipo de comunicação, era de fundamental importância para a continuidade histórica do conhecimento, pois não havia a escrita. A escrita foi um dos mais importantes desenvolvimentos técnicos do ser humano, assim como a fala foi o principal instrumento utilizado no tempo da oralidade (LIMA, 2007, p. 276).

Os estudos de memória estão intrinsecamente ligados à oralidade, uma vez que esta foi por muito tempo o modo de comunicação utilizado antes da escrita e registrado pela 
memória/corpo. Zumthor (1997) afirma que não se pode considerar a oralidade inferior à cultura escrita - mesmo sendo vista de forma equivocada por muitos anos pelo discurso do mundo escriptocêntrico ${ }^{1}$. Segundo o autor, após o surgimento da tecnologia da escrita, a oralidade ainda demonstra vitalidade enquanto uma forma de comunicação, uma vez que diversas manifestações de base oral continuam subsistindo.

Pensando que a memória pode revitalizar de modo permanente o passado e o presente das pessoas (FERNANDES, 2003) é que se pode encontrar um conectivo entre a contação de histórias e a cantoria de viola, enquanto manifestações que carregam em sua construção lembranças, informações e conhecimentos diversos, além de práticas perpassadas de geração a geração por meio da fala e de gestos.

A contação de histórias conduzirá de modo lúdico a transmissão de informações presentes nas memórias dos contadores, ao passo que estimulará as leituras de vida dos integrantes das apresentações (condutores e receptores da mensagem). Os conteúdos destas narrativas não estão repletos apenas de fábulas e personagens que podem ser revividos no imaginário, mas carregam uma imensa bagagem histórica, social e cultural das regiões onde as narrativas são reproduzidas.

A contação de histórias pode ser caracterizada como "um ato de linguagem que faz referência a uma série de ações ou acontecimentos situados no passado sejam esses reais ou ficcionais". O contador busca em sua memória a essência da história enquanto acrescenta elementos formadores de sua própria identidade enquanto sujeito. Então a narrativa tem dois níveis: o ato de fala e a referência aos acontecimentos, aos objetos e às circunstâncias (HANKE, 2003)

A prática da contação tornou-se um dos principais meios de preservação dos valores de uma comunidade. Trata-se de uma atividade de berço cultural e de registro histórico provado pelos diversos contextos socioculturais contemporâneos que ameaçam a prática de potencial construtora de identidade cultural (CALDIN, 2002).

Quando o ouvinte identifica na história elementos presentes nas suas memórias ou na construção delas em seu cotidiano, isto gera mais do que a simples apropriação da narrativa, modifica sua identidade, o modo como se comporta em sociedade e a forma como visualiza o mundo. Essa transformação, perceptível quando o olhar do pesquisador se volta a esse tipo de manifestação, é reforçada teoricamente pelas concepções de Freire (1989) e permite observar

1 Para Lemaire (1994, p.61), a historiografia da literatura é dividida em duas partes: antes e depois da escrita, sendo que esta última é apresentada como única e contínua se sobressaindo diante da anterior. Esse discurso escriptocêntrico é transmitido por meio da elite intelectual, não raras as vezes, preconceituoso, onde o que não se encaixasse naqueles paradigmas era julgado como "menor", "simples" e "ingênuo". 
o quanto a prática da contação de histórias pode trazer reflexões acerca das condições de produção de sentidos e leitura de mundo.

A contação de histórias também pode ser analisada pelo seu poder para estimular o aprendizado e transmitir informações contributivas para a construção da identidade cultural de um indivíduo, mas ela depende da participação e intenção do contador de histórias para executar essa ponte entre o conhecimento cultural e identitário, retido nas narrativas, e o ouvinte.

Quanto à cantoria de viola, esta é uma expressão cultural reconhecida como profissão artística por meio da Lei Federal № 12.198 de 14 de janeiro de $2010^{2}$ e com processo em andamento de registro como Patrimônio Imaterial do Brasil pelo IPHAN ${ }^{3}$, bem como o registro da Literatura de Cordel que tem características semelhantes. Ambas as manifestações se enquadram na descrição do Livro de Registro dos Saberes, em que são inscritos conhecimentos e modos de fazer enraizados no cotidiano das comunidades e, igualmente, no Livro de Registro das Formas de Expressão, em que são inscritas manifestações literárias, musicais, plásticas, cênicas e lúdicas (IPHAN, 2014).

Trata-se da palavra falada, cantada, sentida por todos a seu redor. Em tom de oração, elogio ou escárnio, acompanhado de um parceiro, um pinho e toda uma performance, o poeta emana versos de repente e encontra na plateia coautores de seu espetáculo que, estarrecidos, indignados ou emocionados direcionam a apresentação (SÁ, 2017, p. 19).

Forma peculiar de transmitir informação, que desde tempos remotos é tida como fonte de informação e divertimento, a cantoria de viola, que a princípio ocorria somente em feiras, praças e reuniões familiares, hoje se vê em festivais e congressos em todos os estados do Nordeste e também nas regiões que receberam grande número de imigrantes nordestinos como São Paulo, Brasília e região Norte do país. Segundo Sautchuk (2009, p.1-2),

[...] há regiões em que a admiração pelo repente é mais forte, berço de muitos cantadores e onde cantadores de outros locais costumam se instalar. Em todo o estado da Paraíba há polos de cantoria, dentre os quais ressalto Campina Grande, Patos e Cajazeiras. Nos outros estados, cidades do interior, como Juazeiro do Norte (CE), Mossoró (RN) e Caruaru (PE) reúnem, há décadas, grande número de repentistas. Limoeiro do Norte, Russas, Tabuleiro do Norte e Iguatu, no vale do rio Jaguaribe (CE), congregam cantadores e promotores de cantoria. No vale do rio Pajeú, em Pernambuco, a cantoria constitui uma espécie de cultura oficial em municípios como São José do Egito e Afogados da Ingazeira, e os descendentes de grandes

2 Disponível em: <http://www.planalto.gov.br/ccivil 03/ Ato2007-2010/2010/Lei/L12198.htm>.

Acesso em: 8 abr. 2019.

3 Disponível em: <http://portal.iphan.gov.br/pagina/detalhes/426>. Acesso em: 8 abr. 2019. 
cantadores dali formam uma elite cultural local. As capitais desses estados (Recife, João Pessoa, Natal e Fortaleza) também possuem intensa atividade de cantadores, em decorrência da grande presença ali de migrantes sertanejos.

A cantoria possibilitou aos poetas, antes nômades, ganharem a vida contando as histórias e notícias dos lugares pelos quais passaram. E, mesmo com a mudança de paradigmas, com a inserção das tecnologias nos seus modos de expressão, a cantoria é produzida para disseminação da cultura, na forma de uma tradição passada de geração a geração (de pai para filho) de determinada sociedade e/ou como instrumento de transmissão de informação (LEMAIRE, 2010). Faz parte do universo da oralidade, pois por muito tempo foi mensagem falada, registrada somente na memória (em seu sentido cognitivo) e suas informações passadas adiante através da memorização e repetição dos versos.

Apesar de perdurar como prática cultural, tendo como recurso primordial a memória (como lembrança), a cantoria de viola, atualmente, se utiliza de outros artefatos que a auxiliam na sua preservação (registro) e divulgação. É possível encontrar versos registrados na forma escrita (como cordel), declamados ou cantados em fitas ou discos, DVDs e nas redes de internet. Isso demonstra a capacidade de se reinventar da arte e dos poetas que dela vivem enquanto alimento para a alma, bem como financeiramente. $O$ que se deve ao fato de que, além de ser uma forma de apreciar a poesia e usá-la como válvula de escape para o que se sente, a cantoria de viola é também uma alternativa do poeta/cantador de angariar recursos ao participar dos festivais, ganhando prêmios ou gravando e comercializando seus discos.

Desse mesmo modo, também se fortalece como manifestação artística e cultural, aumentando seu leque de espaço, produção e produtores em todo território brasileiro.

\footnotetext{
Como uma das formas populares de manifestação artística poético-musical do Brasil, circunscreve-se, principalmente, à zona sertaneja da região nordestina. Embora, em todos os seus elementos constitutivos, seja parte da cultura rural, ela também pertence - de fato - à cultura urbana. Várias das razões para sua expansão têm sido as contínuas migrações dos nordestinos, fugindo das secas periódicas e sua consequente inserção nos meios de comunicação, que tem possibilitado a abertura de novos espaços em outros pontos do país (RAMALHO, 2001, p. 3).
}

A cantoria, assim como diversas manifestações culturais e artísticas, não pertence a um só lugar. Tem características próprias que a distinguem das demais e a colocam no âmbito da tradição, embora esteja continuamente se reinventando, buscando novos espaços, apropriando-se de outros elementos e dialogando com outras manifestações a fim de se perpetuar.

Nesse sentido, em se tratando de preservação/salvaguarda e disseminação da informação, a cantoria de viola bem como a contação de histórias são práticas que contribuem 
para a manutenção de uma forma de comunicação que deve(ria) ser discutida nos estudos acadêmicos, pois alia o universo da oralidade, que por muito tempo foi visto como algo "simples e inculto" (LEMAIRE, 2010), ao fazer de uma sociedade rica em cultura e às possibilidades dadas pela memória enquanto produtora, suporte e fonte de informação.

\section{Elementos constitutivos das manifestações}

A contação de histórias e a cantoria de viola, apesar de apresentarem características próprias, têm o berço em comum, são provindas da oralidade, são suportes de informação memorialística que refletem em seu viés a cultura e a identidade da sua região mãe. Além disso, ambas trabalham com a mesma base em essência: indivíduo emissor (cantador ou/e contador), palavra (improvisada e/ou apropriada), performance e público. No caso deste trabalho, as duas atividades estão inseridas e são desenvolvidas na mesma localidade: região do Cariri cearense, o que constitui mais um ponto em comum.

O quadro abaixo apresenta os elementos que constituem as manifestações, as quais são objeto de estudo desta investigação, a partir das informações identificadas nas dissertações "A cantoria de viola como registro de memória e disseminação de informação na região do Cariri: legitimação e contradição" (SÁ, 2017) e "Contações de história na região do Cariri Cearense: memória, identidade cultural e a mediação da leitura" (SOUSA, 2017). Estes trabalhos foram desenvolvidos utilizando pesquisa bibliográfica em literatura pertinente sobre os temas, observação das práticas culturais e entrevista com os participantes de tais manifestações.

\section{Quadro 1 - Elementos constitutivos das manifestações}

\begin{tabular}{|l|l|l|}
\hline ORIGEM & CANTORIA DE VIOLA & CONTAÇÃO DE HISTÓRIAS \\
\hline DEFINIÇÃO & Oralidade e memória & Oralidade e memória \\
\hline $\begin{array}{l}\text { Trata-se da palavra falada, } \\
\text { cantada, sentida por todos a seu } \\
\text { redor. Em tom de oração, elogio } \\
\text { ou escárnio, acompanhado de um } \\
\text { parceiro, um pinho e toda uma } \\
\text { performance, o poeta emana } \\
\text { versos de repente e encontra na } \\
\text { plateia coautores de seu } \\
\text { espetáculo que, estarrecidos, }\end{array}$ & $\begin{array}{l}\text { O ato de expor contos por meio } \\
\text { da figura do narrias literárias. Ela pode } \\
\text { ser compreendida, por exemplo, } \\
\text { como um meio para entender a } \\
\text { cultura de uma determinada } \\
\text { comunidade, visto que na } \\
\text { compilação das mensagens } \\
\text { contidas nas suas narrativas }\end{array}$ \\
\hline
\end{tabular}




\begin{tabular}{|c|c|c|}
\hline & $\begin{array}{l}\text { indignados ou emocionados } \\
\text { direcionam a apresentação (SÁ, } \\
\text { 2017, p. 19). }\end{array}$ & $\begin{array}{l}\text { reside a gravação de memórias } \\
\text { pessoais e coletiva de quem } \\
\text { experimentou épocas ou eventos } \\
\text { históricos, visto que é na tradição } \\
\text { oral que se fundamenta a } \\
\text { identidade cultural mais } \\
\text { profunda de um povo (SOUSA, } \\
2017, \text { p.22). }\end{array}$ \\
\hline CARACTERÍSTICAS & $\begin{array}{l}\text { Cantador (emissor) } \\
\text { Palavra improvisada } \\
\text { Performance } \\
\text { Movência } \\
\text { Público }\end{array}$ & $\begin{array}{l}\text { Contador (emissor) } \\
\text { Palavra apropriada/modificada } \\
\text { Performance } \\
\text { Movência } \\
\text { Público }\end{array}$ \\
\hline
\end{tabular}

Fonte: as autoras (2019).

Para compreender o processo de comunicação, recorreu-se a Jakobson (1991), para quem os estudos linguísticos devem ser analisados sob a égide da teoria da comunicação. $O$ autor recorre ao esquema inclusivo de seis elementos: Contexto; Mensagem; Remetente; Destinatário; Canal e Código. A predominância de cada um dos elementos da comunicação gera seis atitudes estilísticas: emotiva, conativa, referencial, fática, poética e metalinguística. Pode-se perceber, quando se analisam as formas de comunicação de contadores e cantadores, as múltiplas relações intervenientes na linguagem. Elas impedem que se explicitem suas funções sem levar em conta os contextos e as condições histórico-sociais de sua produção e que, embora aparentemente destituídas de carga semântica, as mensagens adquirem um significado quando pronunciadas, ou seja, todo ato comunicacional é um ato social e político. No caso deste estudo, têm-se a evidência deste processo entre o contador/cantador que se apropria/improvisa e modifica/cria a mensagem em seus contos/cantoria e por meio deles emite informação, utilizando-se da narrativa/cantoria como principal meio de suporte e disseminação para a sociedade que a consome, se apropria, recupera e dissemina.

Reconhecendo-se que a Ciência da Informação se preocupa com a informação registrada, embora nos mais variados suportes, o registro é imprescindível como possibilidade de realizar os processos a ela incumbidos (coleta, análise, classificação, descrição, preservação e disseminação são tarefas que precedem uma inscrição). No âmbito da oralidade, são 
encontradas informações tão valiosas quanto aquelas registradas desde sua origem ou as ditas oficiais (SÁ; BUFREM, 2016).

$\mathrm{O}$ ato de se comunicar é inerente ao homem, ao longo dos tempos ele desenvolveu inúmeras formas para exprimir essa ação seja através de imagens, textos, expressão corporal e sons. A transmissão de informações através do ato de narrar é apenas mais um exemplo da diversidade de formas, que as sociedades utilizam para demonstrar suas características únicas, culturais e tradicionais. Embora o foco desta pesquisa tenha sido a região do Cariri Cearense, as práticas e manifestações culturais aqui descritas têm caráter universal.

A oralidade é um campo volátil, tendo como um de seus maiores aspectos caracterizadores a movência (ZUMTHOR, 1997; 2005; 2007), fenômeno que, segundo Zumthor, se refere à dinamicidade das manifestações ou informações do universo oral, ou seja, é aquele movimento que possibilita a modificação, mesmo pequena ou imperceptível, da informação, a depender do contexto e/ou da memória de quem a reproduz.

Esse caráter de movência é por muitos considerado o "tempero" a mais, agregado à tradição oral. No ato da reprodução de alguma informação, o indivíduo corre o risco de esquecer algum trecho, podendo mudar uma palavra por sinônimos ou algo que possa fazer sentido em tal contexto. E, dessa forma, aquele que reproduz torna-se autor e autônomo - já que no mundo oral há certa dificuldade na questão de definição da autoria - e esta autonomia possibilita ao indivíduo uma sensação de pertencimento, de fazer-se, diante da obra, também um artista. Nesse sentido, a informação oral contextualizada é registrada na memória buscando preservar e perpetuar as lembranças e vivências dos indivíduos, que desejam compartilhar ideias e acontecimentos seus com a coletividade, a fim de que o outro possa ter conhecimento do que foi vivido e dessas situações construir conceitos e aprendizado para manutenção das tradições e identidade dos grupos (SÁ; BUFREM, 2016, p. 8).

No caso dos contadores de história, a mobilidade com que os contos são moldados, quase que artesanalmente de acordo com o público ouvinte, suas reações, o lugar e a cultura local, é como se a narrativa se tornasse um líquido que, a depender da "temperatura" do ambiente, se transformasse ao estado que o contador de história bem quiser.

Em relação ao cantador de viola, apesar do seu objetivo ser transmitir determinada mensagem, ela jamais será repetida da mesma maneira que foi dita pela primeira vez, pois sofre influência da memória do cantador, do público do espetáculo e do ambiente em que ambos estão inseridos.

Além disso, o emissor, a palavra, a performance e o público também são elementos que constituem ambas as manifestações e merecem destaque neste trabalho. 0 emissor é quem transmite a informação, seja ela produto da cantoria ou a história, é o protagonista do ato da comunicação. Na cantoria de viola o emissor é o cantador que cria e apresenta seus 
versos no improviso ao som da viola. De acordo com Tavares (2011, p.34), "o violeiro nordestino não é um músico instrumentista: é um poeta, um cantador de versos, e a viola lhe serve apenas como suporte rítmico e harmônico". E na contação de histórias o emissor é o contador, aquele indivíduo que cria ou reproduz histórias, durante as apresentações ele semeia as informações através das histórias que são resgatadas de sua memória ou são reproduzidas através de um suporte informacional, proporcionando ao ouvinte que seja transportado para o centro do universo da história narrada e assim ele possa absorver tudo o que é dito. Pode-se recorrer ao pensamento de Ong (1998) sobre a comunicação que ocorre entre narrador/plateia que vai além das percepções auditivas,

A enunciação oral é dirigida por um indivíduo real, vivo, a outro individuo real, vivo, em um tempo específico e em um cenário real que inclui sempre muito mais do que meras palavras. As palavras faladas constituem sempre modificações de uma situação que é mais do que verbal. Elas nunca ocorrem sozinhas em um contexto simplesmente de palavra (ONG, 1998, p. 118).

A palavra é a mensagem ou informação transmitida por esses sujeitos na sua prática cultural. Na contação de histórias a palavra é a própria história contada, sendo assim ela não é simplesmente fala. Ela é carregada dos significados que Ihe atribuem o gestual, o ritmo, a entonação, a expressão facial e até o silêncio que, entremeando-se ao discurso, integra-se a ela. O valor estético da história contada está, portanto, na conjugação harmoniosa de todos os esses elementos (MATOS; SORSY, 2005). Já na cantoria de viola a mensagem é transmitida por meio de versos musicados, são criados no calor do momento a partir de indicações da plateia ou sorteio de assuntos (mote).

\footnotetext{
Os versos são compostos numa troca comunicativa contínua entre poetas e ouvintes. Ao mesmo tempo em que os versos são produzidos embasados em regras e padrões, a cantoria se dá na forma de diálogo entre o poeta e seu parceiro, bem como dos dois poetas com a plateia. É a interação entre os sujeitos que compõem uma cantoria, os cantadores e o público (SÁ, 2017, p. 29).
}

A exemplo disso, nos versos a seguir, desenvolvidos em forma de Décima, os poetas cantadores dialogam sobre a história da sua profissão, motivados pelo mote em destaque:

IV - Num evento no Rio de Janeiro

Os poetas fizeram desafios

E Bandeira Ihe deu os elogios

Que abalou todo o solo brasileiro

Houve mais dois eventos em Juazeiro 
Mas Campina é quem fez a divisão

Arquivando uma velha geração

Dando vez aos novos militantes

Foram esses os fatos mais marcantes

Da história da nossa profissão.

JB - O histórico da nossa cantoria

Começou lá na Serra do Teixeira

Hugulino hasteou nossa bandeira

Com Nicandro o irmão na companhia

Quando Inácio comprou a alforria

E o escravo poeta Fabião

Derrubaram o poder da escravidão

Mais que Castro em Espumas Flutuantes

Foram esses os fatos mais marcantes

Da história da nossa profissão. ${ }^{4}$

A performance é a forma pela qual a informação é passada pelo emissor, que se dá a partir dos gestos e entonação da voz. O cantador na sua performance pode se utilizar de recursos de prolongamento entre uma palavra e outra e/ou modificar a sílaba tônica, isso porque o ritmo, a musicalidade permite tal mudança. Já na contação de histórias a performance do contador precisa fazer uso da palavra de forma poética e seus gestos não podem ser apenas uma afirmação do que o texto diz, para que os silêncios do leitor sejam respeitados e ampliados.

4 Trecho de versos cantados pelos poetas Ivanildo Vila Nova (IV) e Jonas Bezerra (JB) no I Festival de Repentista de Ceará Diverso, registrado em CD de mesmo nome do evento (faixa 6), acontecido no dia 15 de junho de 2011. 
Durante o procedimento das entrevistas com os contadores de história, uma questão avaliava os processos que os contadores de história utilizam para transmitir as informações contidas nas narrativas.

Sobre isso, Elizabette Gomes Rodrigues (Informação Verbal ${ }^{5}$ ) uma das contadoras entrevistadas, pondera: "Na contação individual uso poucos recursos, alguns fantoches, bonecos feitos de cabaça, ou elementos como lenço, xale, chapéu, alguns instrumentos musicais (percussão) etc. A narrativa é o principal recurso. Geralmente chego ao local, preparo o ambiente usando um tapete, banquinho, acessórios, uma mesinha, antes da chegada dos ouvintes".

Alguns narradores utilizam ferramentas sonoras e visuais, entre objetos que compõem seus personagens ou que ilustram suas histórias, já outros passaram por algum tipo de "mutação" no modo pelo qual transmitem a história e acabam optando em usar seu próprio corpo e voz como elemento para enquadrar à narrativa. Quando o contador optar por usar apenas "o poder da palavra" ela passa a ser mais do que simplesmente a fala. Ela passa a ser carregada de significados (SOUSA,2017). A Contadora de Histórias Maria Elisabete Pacheco, evidencia essa transformação em sua própria formação (Informação Verbal ${ }^{6}$ ) "Antes usava muito adereços, hoje acredito fielmente no poder da palavra, volta e outra uso alguns panos que vão virando tudo dentro das histórias".

Dito isso, o corpo assume um papel importante na transposição do texto presente na memória do sujeito narrador para a narração oral. A ação de movimentar-se durante a contação deve ser verdadeira, gerando credibilidade ao ouvinte perante aquilo que está sendo narrado. A integração entre o texto narrado e a expressão corporal permite ao contador um resultado satisfatório em sua atuação. Cada gesto, cada palavra e cada olhar carregam em si o conjunto de impressões que o narrador pretende transmitir (RAMOS, 2011).

É perceptível no discurso de Malba Tahan (1961) que, quando o contador se identifica com a sua própria narrativa e a conhece, ele passa veracidade para seu ouvinte e assim domina o auditório. Se o contador emprestar seu corpo para conduzir o diálogo entre ele, o texto e o ouvinte, sua performance enriquecerá a linguagem verbal. Mas, para que esse processo de performance aconteça de forma satisfatória, é necessário que o narrador conheça e domine seu processo de recuperação mnemônica, pois além de conhecer sua história e seu público, ele se torna o condutor daquela informação. 
E, por fim, o público que é o receptor, quem recebe a informação e para quem tais práticas culturais acontecem. A plateia é um dos elementos mais importantes para que uma cantoria de viola se realize,

É tida como termômetro e combustível, pois é quem, de modo indireto, direciona o desenrolar das apresentações. A depender das reações esboçadas por seus componentes, seja através de vibrações, aplausos ou bocejos, o poeta percebe se deve continuar a cantar, mudar o rumo do improviso ou findar ali mesmo (SÁ, 2017, p. 29).

Para a contação de histórias, o encontro do contador com o seu público permeia um encontro de gerações, durante suas apresentações. A prática de contar histórias permite a intercomunicação das partes, do contador e do ouvinte, do passado e do presente, permite ao ouvinte e contador vislumbrar o futuro. $\mathrm{O}$ ato de contar as histórias exige do ouvinte $\mathrm{O}$ silêncio, a voz do ouvinte cala para que o texto possa produzir sentidos. Um texto provoca muitos sentidos que vão, no decorrer da contação, mostrando-se ao leitor. Os olhos e os ouvidos do leitor sãos os sentidos que lhe permitem abstrair, construir conceitos e hipóteses, brincar com o texto, aprender com ele, internalizar significados, exteriorizar emoções. É pelos sentidos que o texto é recebido e é por meio deles que o leitor constrói a lógica do enredo ficcional (SOUSA, 2017).

Os recursos que o contador de história utiliza para envolver o seu público são fundamentais para a apresentação do processo estético, assim: a voz, o olhar, o seu estado de espírito, o domínio sobre a história a ser narrada e do público são qualidades de um bom contador de histórias.

\section{Considerações finais}

Durante o processo de escrita das pesquisas que serviram como alicerce para este artigo, por vezes foi pensado se o ato de contar histórias não seria uma cantoria de viola falada, ou se a cantoria de viola não seria uma contação de histórias, composta por poesia e música. Certamente ambas estão intimamente ligadas e muitos dos seus pontos, no processo de criação e transmissão das suas práticas, se confundem.

Este trabalho coloca em foco a contação de história e a cantoria de viola enquanto elementos de disseminação de informação e registro de memória, que representam uma comunidade, uma tradição, suas vozes, sua identidade e cultura. A partir de trabalhos anteriores apresenta a aproximação entre ambas as práticas culturais, seus elementos constitutivos e sua relação com a oralidade e memória.

Das semelhanças encontradas, destaca-se que as duas atividades se originam do mesmo berço (oralidade), estão inseridas e são desenvolvidas na mesma localidade e, por 
último, carregam importantes contribuições no quesito memória e informação (campos de estudo que dialogam com a Cl).

Além disso, os elementos constituintes de cada uma dessas práticas culturais são bastante semelhantes e exercem as mesmas funções: o emissor, a palavra, a performance e o público. Para que a ação da contação de história e a ação da cantoria de viola aconteçam de forma favorável é necessário que todos estes elementos estejam em harmonia: as informações e experiências transmitidas durante a performance tem de ser comum ao emissor e ao público, o ritmo da atividade artesanal prevaleça em que se entrelaçam mão, voz, gesto e palavra, e que exista uma memória e tradição comuns entre emissor e o público, inserindo-os num fluxo narrativo e vivo.

É no seio da atividade narrativa que surge um reencontro de experiências transmitidas de indivíduo para indivíduo, de povo a povo, capaz de deixar impressos na memória das gerações elementos essenciais, para que as tradições das sociedades orais persistam, além das mudanças ocasionadas pelo crescimento da sociedade escrita.

Portanto, o que pode ser observado é que tanto a contação de histórias como a cantoria de viola congregam, elementos semelhantes e também, em relação aos seus atores e suas obras, um repositório de memórias (HOLANDA, 2012) de sua geração, seu povo, tornando-se elementos de representação e conexão da sociedade e suas facetas sociais, econômicas, políticas e culturais.

\section{Referências}

CALDIN, C. F. Voz, presença e imaginação: a narração de histórias e as crianças pequenas. Encontros Bibli Revista Eletrônica de Biblioteconomia e Ciência da Informação, Florianópolis, v. 7, p. 25-38, 2002.

CARIRY, R. Cariri: a nação das utopias. Fortaleza, 2001.

FREIRE, P. A importância do ato de ler: três artigos que se completam. São Paulo: Cortez, 1989.

FERNANDES, D. L. A literatura infantil. São Paulo: Edições Loyola, 2003.

HANKE, Michael. Narrativas orais: formas e funções. Contracampo (UFF), Rio de Janeiro, v. 7, p. 117-126, 2003.

HOLANDA, L. Memória: multiplicidade e permanência. IRIS: Revista de Informação, Memória e Tecnologia, Recife, v. 1, n. 1, p. 17-25, jul./dez. 2012. Disponível em: <http://www.repositorios.ufpe.br/revistas/index.php/IRIS/article/view/7/12>. Acesso em: 15 abr. 2019. 
JAKOBSON, R. Linguística e poética. In: JAKOBSON, R. Linguística e comunicação. São Paulo: Cultrix, 1991.

LE COADIC, Y. A ciência da informação. Brasília: Briquet de Lemos/Livros, 1994. 122 p.

LEMAIRE, R. Repensando a história literária. In: HOLLANDA, Heloísa Buarque de (org.). Tendências e impasses. O feminismo como crítica da cultura. Rio de Janeiro: Rocco, 1994.

LEMAIRE, R. "Tradições que se refazem". Revista Estudos de Literatura Brasileira Contemporânea, Brasília, n. 35, p. 17-30, jan./jun. 2010,. Disponível em: <http://www.gelbc.com.br/pdf_revista/3501.pdf> Acesso em: 15 abr. 2019.

LIMA, D. F.C. Herança cultural (re)interpretada ou a memória e a instituição museu releitura e reflexões. Museologia e Patrimônio. Rio de Janeiro, v. 1, n. 1, p. 33-43, jul./dez. 2007.

MATOS, G. A, SORSY, L. O ofício do contador de histórias. São Paulo: Martins Fontes, 2005.

MONTEIRO, S. D. CARELLI, A. E. PICKLER, M. E. V. A Ciência da Informação, Memória e Esquecimento. DataGramaZero -Revista de Ciência da Informação. Rio de Janeiro, v. 9, n. 6, dez. 2008. Disponível em: <http://www.dgz.org.br/dez08/Art_02.htm> Acesso em: 15 abr. 2019.

ONG, W. J. Oralidade e cultura escrita: a tecnologização da palavra. São Paulo: Papirus, 1998.

RAMOS, A. C. Contação de histórias: um caminho para a formação de leitores? Dissertação de Mestrado em Educação. Universidade Estadual de Londrina, 2011.

RAMALHO, E. B. Cantoria nordestina: pensando uma estética da cultura oral. Ensaio à Universidade Estadual do Ceará, 2001. Disponível em <http://www.iaspmal.net/wpcontent/uploads/2011/12/Ramalho.pdf>. Acesso em: 15 abr. 2019.

RODRIGUES, L. G. A arte das narrativas orais urbanas: performance, história, memória e ficção. Porto Alegre: UFRGS, 2010.

SÁ, P. I. B.; BUFREM, L. S. O registro da cantoria de viola enquanto informação memorialística e sua contradição. In: ENCONTRO NACIONAL DE PESQUISA EM CIÊNCIA DA INFORMAÇÃO,12., GT 10. Salvador, 2016. Anais...Salvador: Universidade Federal da Bahia, 2016.

SÁ, P. I. B. A cantoria de viola como registro de memória e disseminação de informação na região do Cariri: legitimação e contradição. Dissertação (Mestrado), Universidade Federal de Pernambuco, Centro de Artes e Comunicação. Ciência da Informação, 2017.

SAUTCHUK, J. M. M. A Poética do Improviso: prática e habilidade no repente nordestino. Tese (apresentada ao Departamento de Antropologia da Universidade de Brasília para obtenção do Título de Doutor em Antropologia). Brasília (DF): 2009. Disponível em <http://repositorio.unb.br/bitstream/10482/5091/1/Tese\%20DAN-BCE.pdf> Acesso em: 15 abr. 2019.

SOUSA, A. L. M. Contações de história na região do Cariri Cearense: memória, identidade cultural e a mediação da leitura. Dissertação de Mestrado em Ciência da Informação. Universidade Federal do Pernambuco. 2017. 
TAHAN, M. A arte de ler e contar histórias. Rio de Janeiro: Conquista, 1961.

TAVARES, B. Função da música na cantoria de viola. Synergies Brésil, n. 9, 2011.

ZUMTHOR, P. A letra e a voz: a literatura medieval. São Paulo: Cia. Das Letras, 1993.

ZUMTHOR, P. Introdução à poesia oral. São Paulo: Educ/Hucitec, 1997.

ZUMTHOR, P. Escritura e nomadismo. São Paulo: Ateliê, 2005.

ZUMTHOR, P. Performance, recepção e leitura. São Paulo: Cosac Naify, 2007. 